\title{
Mental States Peculiarities of Students Proclivity for Drug Addiction
}

\author{
Elena A. Cheverikina \\ The Institute of Pedagogic and Psychology of Professional Education of Russian Academy of Education, Kazan, Russia \\ Email: cheverikina@mail.ru \\ Igor O. Vasyukhno
}

The Main Department of the Ministry of Internal Affairs of Russia in Moscow region, Moscow, Russia

Faniya Z. Siafetdinova

Kazan National Research Technological University, Kazan, Russia

Ekaterina V. Mokeyeva

Kazan (Volga region) Federal University, Kazan, Russia

Venera Sh. Yusupova

Lucia F. Chukmarova

Naberezhnye Chelny Branch of the Institute of Economics, Management and Law, Naberezhnye Chelny, Russia

Vasily P. Kovalev

Chuvash State Pedagogical University named after I.Y. Yakovlev, Cheboksary, Russia

\section{Doi:10.5901/mjss.2015.v6n2s3p9}

\section{Abstract}

Tendency to drug addiction has an adverse effect on success of socialization and personal and professional students' formation. There is a risk of proclivity development for addiction, for a disease that can lead to full degradation of the personality. One of the reasons of drug addiction is students' being unable to manage their mental states. The features of mental students' conditions of drug addictionproclivity, the features of their dominating states and a relief of mental states were studied in the research in order to learn the statistical analysis of distinction of reliability of average values. So the correlation analysis was carried out. Data were processed by the program of statistical data processing of SPSS 22.0. It is established that expressiveness of all mental states among students with high tendency to drug addiction is weaker, though negative states are expressed more strongly. Tendency to drug addiction among students is caused by stronger expressiveness of the mental states connected with experiences, and by weaker expressiveness of the mental states connected with physiological reactions. The data obtained during research will allow the correcting of the psychology and pedagogical programs directed at level tendency decrease to drug addiction among students taking into account the features of their mental states.

Keywords: mental states; dominating states; relief of mental states; proclivity for drug addiction; students.

\section{Introduction}

The mental state unlike such concepts as "mental process", characterizing dynamic manifestations of mentality, or "mental property" which on the contrary, indicates stability of its manifestations, is used for conditional allocation in mentality of the individual of rather static moment in psychology (Ldokova, 2006). In other words, the psychological state is defined as the steady characteristic in a certain period of person's mental activity.

Also it is necessary to emphasize that, as a rule, mental states are jet states, that is a certain system of responses to certain behavioral or any other situation. And thus all mental states that differ from individual traits are the current 
modification of any person's mentality. (Prokhorov, 2004).

The addicted person differs from prevalence of negative mental states which are forced out or replaced by the changed states in the course of acts of addicted behavior for the improvement of the common person's state. The following features of mental states are inherent in an addicted person: the raised level of a stress and low resilience to it, the raised level of aggression and frustration (Ludwig, 2012).

Students, both in the course of educational activity and in everyday life are influenced by various stressful factors that negatively impact their mental state and can lead to addiction actualizing of the person. It can be shown in drug addiction.

Studying students' mental states and their proclivity for drug addiction allow the revealing of their features which become targets for further psychological work on their correction to decrease the level of tendency to their drug addiction.

\section{Material and Methods}

Object of research: students with different level of tendency to drug addiction.

Object of research: the features of mental states that cause drug addiction.

Research problems: to carry out the theoretical analysis of scientific literature on a problem of mental states among students inclined to drug addiction; to do empirical research using the corresponding means among students for detection of features of the mental states influencing formation of tendency to drug addiction.

30 students of the Kazan (Volga) Federal University, Kazan; 32 students of the Kazan National Research Technological University, Kazan and 35 students of Naberezhnye Chelny Branch of the Institute of Economics, Management and Law, Naberezhnye Chelny took part in the empirical research.

Research was done with the following techniques:

1. Technique of definition of the dominating state, directed at definition of characteristics of moods and some other characteristics of personal level of mental states by means of value judgment surveyed (Sandpipers, 2003).

2. Technique "A relief of a mental state" (Prokhorov, 2004) for identification of the main parties of a mental state: mental processes, physiological reactions, experiences and behavior.

3. Technique of definition of mental states (Prokhorov, 2004), directed at the identification of degree of expressiveness of positive and negative mental states.

4. The questionnaire "Susceptibility to addiction" (Cheverikina and Gryaznov, 2012) to identify the students at risk of drug abuse.

\section{Results}

Average values of defining technique of a dominating state among students with different level of tendency to drug addiction are presented in table 1.

Table 1. Average values and results of T-criterion of Student on a technique of definition of a dominating state at students with low and high level of tendency to drug addiction

\begin{tabular}{|l|c|c|c|c|}
\hline & Low Level of Tendency & High Level of Tendency & \multicolumn{2}{|c|}{ T-criterion for Equality of Average } \\
\cline { 4 - 5 } & to Drug Addiction & to Drug Addiction & t & Two- sided meaning \\
\hline Activity- passivity & 32 & 33,28 & 0,485 & 0,631 \\
\hline Vigor-despondency & 25 & 23,78 & $-0,632$ & 0,531 \\
\hline Vitality ( high-low) & 27,14 & 24,72 & $-0,838$ & 0,407 \\
\hline Relaxedness-strain & 24,57 & 24,56 & $-0,005$ & 0,996 \\
\hline Tranquility-anxiety & 24,67 & 25,06 & 0,124 & 0,902 \\
\hline Stability-instability of emotions & 26,47 & 24 & $-0,766$ & 0,448 \\
\hline Satisfaction-dissatisfaction with life & 31,38 & 29,56 & $-0,576$ & 0,568 \\
\hline Positive-negative image of oneself & 22,57 & 17,61 & $-2,928$ & $0,006^{\star}$ \\
\hline
\end{tabular}

* - differences of average are reliable at level $p \leq 0,01$

Students with high tendency to drug addiction have indicators on scales vigor-despondency; stability-instability of emotions, satisfaction-dissatisfaction with life and a positive-negative way of living is lower, than students with low and 
average tendency. They have a lowered, sad mood, despondency, the negative emotional background prevails. Students with high tendency to drug addiction are inclined to disappointment with a course of events, narrowing of interests; they see future in gloomy tone, the sense of the future isn't clear for them. Emotional stability is reduced, they get into emotional excitement easily, their mood is changeable, their irritability is increased and negative emotional tone prevails. Dissatisfaction with life as a whole, its course, process of self-realization and subjects develops the main vital events. They have low estimate of personal success. A person hasn't find himself completely, is reserved, hasn't felt reliable internal support, hasn't an ability to find truthful answers. Leaving in doubts which allows evading from need to make a vital choice is often characteristic for the person who is listening first of all to himself, assuming responsibility that happens to him. Students with high tendency to alcoholism have low extent of acceptance of negative attitude especially to themselves as well. But on a scale of activity- passivity they on the contrary have higher indicators than students with the low and average level of tendencies to drug addiction. So they have inherent expressed active, optimistic relation to a life situation, a readiness for overcoming obstacles, belief in the opportunities. They have power to overcome the obstacles and achieve the purposes. Their vigor is higher, than the majority of people have.

Therefore, it is possible to draw a conclusion that the tendency of students with drug addiction is expressed in the following dominating mental states: despondency, negative emotional background, decrease in emotional stability, low satisfaction with life and the achievements, leaving in doubts and a negative way of living.

Average values on scales of diagnostics technique of mental conditions among students with different level of tendency to drug addiction are presented in table 2.

Table 2. Average values and results of T-criterion of Student on a technique of definition of mental state among students with low and high level of tendency to drug addiction

\begin{tabular}{|l|c|c|c|c|}
\hline & Low Level of Tendency & High Level of Tendency & \multicolumn{2}{|c|}{ T-criterion for Equality of Average Values } \\
\cline { 4 - 5 } & to Drug Addictiony & to Drug Addiction & & Two-sided Meaning \\
\cline { 4 - 5 } & 52,07 & 45,73 & $-3,403$ & $0,002^{*}$ \\
\hline Positive states of activity & 51,74 & 47,47 & $-0,703$ & 0,487 \\
\hline Negative states of activity & 52,85 & 47,37 & $-4,332$ & $0,000^{*}$ \\
\hline Negative states of communication & 50,52 & 48,49 & $-0,215$ & 0,831 \\
\hline Positive attitude of communication & 49,30 & 46,57 & $-1,736$ & 0,092 \\
\hline Negative attitude to others & 53,25 & 48,69 & $-0,637$ & 0,528 \\
\hline Positive psycho-physiological states & 53,35 & 46,28 & $-5,264$ & $0,000^{\star}$ \\
\hline Negative psycho-physiological states & 49,61 & 51,85 & $-0,230$ & 0,819 \\
\hline Positive emotional states & 53,08 & 45,48 & $-3,200$ & $0,003^{*}$ \\
\hline Negative emotional states & 51,05 & 46,48 & $-0,156$ & 0,877 \\
\hline Positive determined states & 49,46 & 46,75 & $-0,939$ & 0,354 \\
\hline Negative determined states & 53,86 & 47,64 & $-0,450$ & 0,655 \\
\hline Positive intelligent states & 50,16 & 48,88 & $-2,082$ & $0,045^{\star \star}$ \\
\hline Negative intelligent states & 53,12 & 49,60 & $-1,110$ & 0,275 \\
\hline
\end{tabular}

* - differences of average are reliable at level $p \leq 0,01$

** - differences of average are reliable at level $p \leq 0,05$

Students with high tendency to drug addiction are observed to have the following features: they have lower general background of expressiveness of mental states than teenagers with low tendency. But at the same time they are not observed to have a strong difference between expressiveness of negative and positive mental states though indicators on negative mental states are a little higher. Negative psycho-physiological states among students with high tendency to drug addiction obviously expressed peak on a scale is observed in a profile of mental states.

Therefore, it is possible to draw a conclusion that students with high tendency to drug addiction have weaker expressiveness of all mental states, thus negative states are expressed more strongly. Negative psycho-physiological states are strongly expressed among teenagers with high tendency to drug addiction.

Average values on integrated indicators of a technique "A relief of mental states" among students with different level of tendency to drug addiction are presented in table 3. 
Table 3. Average values and results of T-criterion of Student on a technique of definition of a relief of mental states among students with low and high level of tendency to drug addiction

\begin{tabular}{|l|c|c|c|c|}
\hline & & & \multicolumn{2}{|c|}{$\begin{array}{c}\text { T-criterion for Equality of } \\
\text { Average Values }\end{array}$} \\
\hline & $\begin{array}{c}\text { Low Level of Tendency } \\
\text { to Drug Addiction }\end{array}$ & $\begin{array}{c}\text { High Level of Tendency to Drug } \\
\text { Addiction }\end{array}$ & Two-sided Meaning \\
\hline Psyche States & 83,72 & 70,09 & 0,070 & 0,945 \\
\hline Physiological Reactions & 74,17 & 68 & $-0,756$ & 0,461 \\
\hline Emotions & 79,33 & 74,52 & $-0,786$ & 0,443 \\
\hline Behavior & 87,5 & 70 & 1,624 & 0,124 \\
\hline
\end{tabular}

All mental states are expressed more weakly among students with high level of tendency to drug addiction than among teenagers with low level of tendencies. But the indicators of mental states connected with experiences are higher in their profile, and the indicators connected with physiological reactions are lower than indicators of other mental states.

Therefore, it is possible to draw a conclusion that tendency to drug addiction among students is caused by stronger expressiveness of the mental states connected with experiences, and weaker expressiveness of the mental states connected with physiological reactions.

We have carried out the correlation analysis of the obtained data for specification of interrelation of mental states and tendency to drug addiction among students. Its results are presented in table 4.

Table 4. Results of the correlation analysis of interrelation of mental states and tendency to drug addiction among students

\begin{tabular}{|l|c|}
\hline Mental States & Tendency to Drug Addiction \\
\hline Activity-passivity & 0,047 \\
\hline Vigor-despondency & $-0,003$ \\
\hline Vitality (high-low) & 0,104 \\
\hline Relaxedness-strain & 0,072 \\
\hline Tranquility-anxiety & 0,021 \\
\hline Stability-instability & 0,086 \\
\hline Satisfaction-dissatisfaction with life & 0,048 \\
\hline Positive-negative image of oneself & $0,317^{\text {** }}$ \\
\hline Positive states of activity & 0,134 \\
\hline Negative states of activity & 0,128 \\
\hline Positive states of communication & 0,171 \\
\hline Negative states of communication & 0,057 \\
\hline Positive attitude to others & $-0,081$ \\
\hline Negative attitude to others & 0,131 \\
\hline Positive psycho-physiological states & $-0,269^{* *}$ \\
\hline Negative psycho-physiological states & $-0,010$ \\
\hline Positive emotional states & 0,165 \\
\hline Negative emotional states & 0,091 \\
\hline Positive determined states & 0,047 \\
\hline Negative determined states & 0,159 \\
\hline Positive intelligent states & $-0,024$ \\
\hline Negative intelligent states & 0,119 \\
\hline Psyche processes & $-0,206$ \\
\hline Physiological reactions & $-0,168$ \\
\hline Emotions & 0,018 \\
\hline Behavior & $-0,340 *$ \\
\hline **. Correlation is significant at level 0,01 (two-sided). & \\
$*$ *. Correlation is significant at level 0,05 (two-sided). & \\
\hline
\end{tabular}

The carried-out correlation analysis confirmed the link of tendency to drug addiction with the mental states caused by negative attitude itself. It is established that tendency to drug addiction is connected with such conditions of mental 
processes, as figurativeness of representations, thinking and attention. Students with high tendency to drug addiction have worse physiological reactions such as muscular tone and sweating. Commitment, reasonableness, control, adequacy and stability decrease in the behavioral sphere. In a whole tendency to drug addiction is connected with deterioration of the mental states connected with behavior.

\section{Discussions}

The drug addiction problem is actively studied recently by foreign scientists in the different directions. Motives of involvement of young people who take drugs and a role of psychologists-consultants in decreasing risk of drug addiction formation (Chado, 2014) are considered. Psychosocial aspects of drug addiction formation and influence of life skills on efficiency of the self-help of the youth inclined to drug addiction (to Golestan, Namayandeh, Anjomshoa, 2011) are studied. It is claimed that training of life skills and formation of social competence reduce risk of recurrence of drug addiction treatment among teenagers and young people.

In Russian psychology the problem of drug addiction and the connected with it psychological and social violations are also widely studied. So, much attention is paid to studying social and psychological reasons and drug addiction consequences (Gryaznov, 2005), social and psychological features of the students inclined to drug addiction and alcoholism (Cheverikina et al, 2015), interrelations of tendency to drug addiction with aggressiveness among students (Gerasimova V. V., 2013). Psychological features of prevention of drug addiction in the young people surroundings (Garifullin, 2009), the organization of anti-narcotic work in a student's hostel (Kuznetsova, Faskhutdinov, 2006) were studied. The separate attention was paid to studying of the I-concept of drug addicts (Khusainova, Rakhimov, 2006). Attempts of the forecast of mental conditions of people with opium drug addiction (Korobeynikova, 2005), etc. were made.

But, in spite of the fact that problems of drug addiction are studied quite widely, researches of features of mental states among students inclined to drug addiction, wasn't carried out.

\section{Conclusion}

High tendency to drug addiction is expressed in the following dominating mental states among students: despondency, negative emotional background, decrease in emotional stability, low satisfaction with life and the achievements, leaving in doubts and a negative image of themselves.

Negative psycho-physiological states among students with high tendency to drug addiction are strongly expressed.

As it is established that students with low and high tendency to drug addiction have positive reliable distinctions of average values on scales positive activity states, positive conditions of communication, positive physiological states, positive states and positive intellectual states, teenagers with high tendency to drug addiction all these psychological states are expressed much lower and have negative character.

The carried-out correlation analysis confirmed the link of tendency to drug addiction with the mental states caused by negative attitude itself. Tendency to drug addiction increases at decrease in psycho-physiological states. In a whole tendency to drug addiction is connected with deterioration of mental states connected with behavior.

\section{Recommendation}

The revealed features of mental conditions of students with high tendency to drug addiction have to be considered when developing the anti-narcotic psychology and pedagogical programs directed at decrease in level of tendency to drug addiction among students. For minimization of risk of students' involvement in taking drugs, it is important to teach them to operate the mental state in various stressful situations, to change negative states for positive, without resorting to the help of psychoactive agents.

\section{References}

Cheverikina EA, Grjaznov AN. (2012). Technique of diagnostics of tendency to students' addiction, in the proceedings of the 2012 international scientific and practical conference "Professional features of social work with children and youth: questions of the theory and innovative practice in training of students for work in this sphere", Kazan, 316-319.

Cheverikina E.A., Kora N.A., Badalyan J.V., Klimova T.V., Yeremeyeva T.S., Mokeyeva E.V. \& Masalimova A.R. (2015). The Correlation between Parental Attitude and Susceptibility to Drug Addiction among Students. Asian Social Science, Vol. 7, No. 1, 6-11, oi:10.5539/res.v7n1p5. 
Garifullin R.R. (2009). Psychological bases of effective prevention of drug addiction. Kazan pedagogical journal, 9-10, $133-142$.

Gerasimova V.V. (2013). Social and psychological features of students with the auto-aggressiveness inclined to alcoholic and narcotic addictions. Kazan pedagogical journal, 1 (96), 152-157.

Gryaznov A.N. (2005) Social and psychological problems and drug addiction consequences. Neurologic messenger, XXXVII (1-2), 60 66.

Khusainova N. Yu., Rakhimova A.F. (2006). I - the concept of the drug addict. Kazan, "New knowledge", 186.

Korobeynikova Yu.V. (2005). The forecast of mental conditions of people with opium drug addiction (from a position of multiracial diagnostics). M. S. thesis, Moscow, 198.

Kuznetsova E.A., Faskhutdinov H.S. (2006). Organization of anti-narcotic work in a student's hostel. Kazan: "New knowledge", 64.

Ldokova G.M. (2006). Negative mental conditions of students in situations with an uncertain way out. Yelabuga: JSC Almedia publishing house, 161.

Ludvig AM. (2012). The changed conditions of consciousness. In the Changed conditions of consciousness, Moscow, the Kognitocenter, 36-50.

Mohammed Chado. (2014). Drug abuse/addicts in schools; the role of school counselor. N Y Sci J, 7(2),62-65.

Prokhorov AO. (2004). Praktikum on psychology of states. St. Petersburg, Speech, 476.

Samira Golestan, Hajar Namayandeh, Ali Anjomshoa, (2011). The Influence of Life Skills with respect to Self-Help Approach on Relapse Prevention in Iranian Adolescents Opiate Addicts. Journal "American Science".7(6), 198-202.

Sandpipers LV. (2003). The instruction to diagnostics of mental states techniques, moods and spheres of feelings. Description of techniques, instructions for application. St. Petersburg, 64. 